\title{
JPEB
}

Jurnal Penelitian Ekonomi dan Bisnis, 5 (1), 2020, Hal: 27 - 38

http://www.jpeb.dinus.ac.id

\section{PENGUKURAN TINGKAT EFISIENSI USAHA KECIL DAN MENENGAH DI KARESIDENAN SURAKARTA TAHUN 2015-2016}

\author{
Tia Putri Ariyani ${ }^{1}$ dan Malik Cahyadin ${ }^{2}$. \\ ${ }^{1,2}$ Program Studi Ekonomi Pembangunan, Fakultas Ekonomi dan Bisnis, \\ Universitas Sebelas Maret \\ Jalan Ir. Sutami No.36A Kentingan Surakarta, Indonesia \\ *Corresponding Author: malikcahyadin@gmail.com
}

Diterima: Juni 2019; Direvisi: Desember 2019; Dipublikasikan: Maret 2020

\begin{abstract}
SMEs play an important role in the national economy. Therefore, stakeholders need to pay attention to develop SMEs by doing efficiency. This research aims to determine the value of the technical, cost, and allocate efficiency of SMEs in Surakarta residency during 2015 - 2016. This research uses Data Envelopment Analysis (DEA) program. The input variable consists of labor, while the output variables consist of sale, asset, and profit. The results of this research show that the average values of technical and cost efficiency are equal. The SEMs of Sukoharjo Regency have average value of technical and cost efficiency in 2015 are 0.850 and increase to 0.864 in 2016. The SMEs of Wonogiri Regency have an efficiency value of 0.746 and increase to 0.755. The SMEs in Karanganyar Regency have an improved efficiency value from 0.648 to 0.735. The efficiency value of SMEs in Surakarta City decreases from 0.692 to 0.691. The efficiency of SMEs in Sragen Regency also decreases from 0.592 to 0.562. The allocate efficiency shows that SMEs in Surakarta Residency are effective. This research recommends that SME owners and local government need to stimulate input utilization to produce maximum output. Furthermore, SME owners also need to manage the availability of input appropriately.
\end{abstract}

Keywords: Efficiency; SME; DEA

\begin{abstract}
ABSTRAK
UKM berperan penting dalam perekonomian nasional. Untuk itu, para stakeholders diharapkan mempunyai perhatian terhadap perkembangan UKM melalui penerapan efisiensi. Tujuan penelitian ini adalah untuk mengetahui nilai efisiensi teknis, biaya, dan alokatif UKM di Karesidenan Surakarta tahun 2015-2016. Metode yang digunakan adalah program Data Envelopment Analysis (DEA). Variabel input meliputi tenaga kerja sedangkan variabel output adalah omset, asset, dan keuntungan. Hasil penelitian menunjukkan bahwa nilai rata-rata efisiensi teknis dan biaya adalah sama. Nilai rata-rata efisiensi teknis dan biaya UKM Kabupaten Sukoharjo tahun 2015 sebesar 0.850 meningkat menjadi 0.864 di tahun 2016. UKM Kabupaten Wonogiri mempunyai nilai efisiensi sebesar 0.746 meningkat menjadi 0.755 . UKM Kabupaten Karanganyar juga meningkat nilai efisiensinya dari 0.648 menjadi 0.735. Efisiensi UKM Kota Surakarta menurun dari 0.692 menjadi 0.691 sedangkan UKM Kabupaten Sragen mempunyai nilai efisiensi dari 0.592 menjadi 0.562 . Hasil efisiensi alokatif menunjukkan bahwa semua UKM di Karesidenan Surakarta sudah efisien. Rekomendasi penelitian ini adalah pelaku usaha UKM dan pemerintah daerah sebaiknya mendorong pemanfaatan input yang dapat menghasilkan output secara maksimal. Selain itu, pelaku usaha UKM juga perlu mengelola ketersediaan dan pengelolaan input secara tepat.
\end{abstract}

Kata Kunci : Efisiensi; UKM; DEA 


\section{PENDAHULUAN}

Usaha Mikro Kecil dan Menengah (UKM) merupakan salah satu jenis usaha yang dijalankan oleh pelaku ekonomi di Indonesia. Pada saat krisis ekonomi UKM di Indonesia relatif mampu mempertahankan usahanya karena mayoritas UKM tidak memiliki hutang luar negeri, belum bankable, proses produksi masih menggunakan bahan baku lokal dan orientasi pada ekspor belum penuh (Malik, 2015). Oleh sebab itu, keberadaannya menjadi salah satu penggerak perekonomian di Indonesia yang relatif strategis.

Miroljub \& Petar (2010) menjelaskan bahwa UKM tidak terpengaruh ketika Serbia berada dalam masa krisis ekonomi. Madalina (2013) juga menyatakan bahwa UKM di Romania mampu mengatasi krisis dan berperan penting dalam keberlangsungan perekonomian negara. Selanjutnya, Holban \& Razvan (2009) mengemukakan bahwa UKM memiliki pengaruh positif dalam memperbaiki perekonomian dari masa krisis ekonomi. Selain itu, Penchev (1998) berpendapat bahwa UKM penting dalam pengembangan industri yang berkelanjutan di masa depan sehingga berdampak positif bagi perekonomian negara.

UKM menyumbang PDB cukup besar bagi Indonesia. Data dari Kementerian Koperasi dan UKM (2014) menunjukkan bahwa PDB di Indonesia yang ditopang oleh skala UKM maupun Usaha Besar (UB) mengalami peningkatan. Hal ini membuktikan bahwa struktur perekonomian Indonesia adalah grass-root economy yang artinya ditopang oleh jutaan perusahaan berskala mikro (micro enterprise) dan perusahaan kecil (small-scale enterprise) (Malik, 2015).

\begin{tabular}{ccccc}
\multicolumn{4}{l}{ Tabel } & \multicolumn{4}{c}{ Rasio UKM di Jawa Tengah terhadap UKM di Indonesia Tahun 2016} \\
\hline No & \multicolumn{1}{c}{ Indikator } & Jawa Tengah & Indonesia & Rasio (\%) \\
\hline 1. & Jumlah UKM (unit) & $4,170,852$ & $26,675,857$ & 15.64 \\
2 & Jumlah Tenaga Kerja & $8,327,650$ & $61,773,672$ & 13.48 \\
& (orang) & & & \\
\hline
\end{tabular}

Tabel 1 menjelaskan rasio jumlah UKM Jawa Tengah terhadap Indonesia tahun 2016 sebesar $15.64 \%$. Sementara itu, penyerapan tenaga kerja oleh UKM Jawa Tengah terhadap Indonesia adalah sebesar $13.48 \%$. Angka ini menggambarkan bahwa Provinsi Jawa Tengah merupakan wilayah yang berperan aktif dalam pengembangan UKM. Selain itu, UKM juga berperan penting dalam penyerapan tenaga kerja dalam rangka mengurangi pengangguran. Hal inilah yang menjadi salah satu kelebihan UKM yaitu bersifat padat karya (Kuncoro, 2007). Horbach (2016) menambahkan bahwa mayoritas pelaku UKM lebih memungkinkan untuk mengembangkan ide/gagasan baru sehingga terdapat banyak variasi produk baru yang ada di pasar. Hal tersebut menjadi nilai tambah pelaku UKM dalam memasuki pasar dibandingkan perusahaan besar dan mapan yang sulit untuk mengubah jalur inovasi mereka. Hal inilah yang menyebabkan kegiatan UKM sering dijadikan dasar penggerak pelaku ekonomi untuk mencari keuntungan di pasar.

Peran penting UKM perlu didorong oleh kinerja usaha yang kuat dan kredibel. Efisiensi dan efektivitas adalah dua cara pengukuran kinerja yang dapat dilakukan. Efektivitas merupakan ukuran untuk melihat ketepatan pencapaian tujuan kebijakan yang berorientasi pada hasil, aksesibilitas, kualitas dan kelayakan. Sementara itu, efisiensi merupakan ukuran yang berkaitan dengan penggunaan sumber daya (Worthington \& Dollery, 2000 dalam Porcelli, 2009). Produksi suatu barang/jasa dikatakan efisien apabila dapat menghasilkan output maksimal dengan menggunakan sejumlah input (biaya) yang minimum (Greene, 1997 dalam Porcelli, 2009).

Pemerintah pusat dan daerah juga telah menetapkan kebijakan dalam rangka pengembangan dan pemberdayaan UKM. Kebijakan tersebut diwujudkan dalam bentuk UndangUndang Nomor 20 Tahun 2008 tentang Usaha Mikro, Kecil, dan Menengah (UKM). Pemerintah Kota Surakarta telah menerbitkan Peraturan Daerah Nomor 5 Tahun 2014 Tentang Pemberdayaan UKM. Selain itu, Pemerintah Kabupaten Sukoharjo juga menerbitkan Peraturan Daerah Nomor 7 Tahun 2017 Tentang Penataan dan Pembinaan Pasar UKM. Kemudian, 
Tia Putri Ariyani dan Malik Cahyadin : Pengukuran Tingkat Efisiensi Usaha Kecil Dan Menengah Di Karesidenan Surakarta Tahun 2015-2016

Pemerintah Kabupaten Sragen juga menerbitkan Peraturan Daerah Nomor 3 Tahun 2013 Tentang UKM.

Penelitian ini akan memfokuskan pada perhitungan dan analisis efisiensi teknis, biaya, dan alokatif UKM di Karesidenan Surakarta. Hasil penelitian ini diharapkan dapat menjadi rujukan bagi pelaku usaha UKM dan pemerintah daerah dalam rangka mendorong usaha UKM yang efisien dan berkelanjutan. Artinya bahwa pelaku UKM dapat mengelola dan menjamin ketersediaan input. Selain itu, para pelaku UKM juga dapat menghasilkan output yang berkualitas dan kompetitif.

Kontribusi penelitian ini adalah perhitungan empiris efisiensi teknis, biaya dan alokatif pada UKM di Karesidenan Surakarta. Ketiga perhitungan tersebut digunakan untuk melihat secara komprehensif tingkat efisiensi UKM di sembilan sektor ekonomi pada tahun 2015-2016. Dengan demikian, hasil penelitian ini melengkapi penelitian-penelitian empiris sebelumnya karena hanya fokus pada efisiensi teknis atau biaya.

Pertanyaan penelitian penelitian ini adalah: (a) Bagaimana nilai efisiensi teknis UKM di masing-masing sektor ekonomi di Karesidenan Surakarta ?; (b) Bagaimana nilai efisiensi biaya UKM di masing-masing sektor ekonomi di Karesidenan Surakarta ?; dan (c) Bagaimana nilai efisiensi alokatif pada sektor UMKM di masing- masing wilayah Eks Karesidenan Surakarta?.

Organisasi tulisan ini terdiri atas enam bagian. Bagian pertama adalah pendahuluan yang membahas perkembangan UKM di Jawa Tengah dan beberapa studi empiris. Bagian kedua adalah tinjauan pustaka yang menjelaskan konsep UKM berdasarkan undang-undang dan teori industri. Bagian ketiga adalah metode penelitian yang menginformasikan data dan pendekatan DEA. Bagian keempat adalah hasil dan pembahasan yang mendeskripsikan hasil perhitungan efisiensi teknis, biaya dan alokatif di masing-masing sektor ekonomi di wilayah Karesidenan Surakarta. Bagian kelima adalah simpulan sedangkan bagian terakhir adalah referensi.

\section{TINJAUAN PUSTAKA}

Pemerintah telah menetapkan dan memberlakukan Undang-Undang Nomor 20 Tahun 2008 tentang Usaha Mikro, Kecil, dan Menengah (UMKM). Menurut Fajar (2016) keberadaan undang-undang ini menjadi bukti bahwa pemerintah menjaga ketahanan ekonomi nasional yang sebagian besar dilakukan oleh pelaku usaha UMKM.

Menurut UU Nomor 20 tahun 2008 bahwa usaha mikro diartikan sebagai "usaha produktif milik orang perorangan dan/atau badan usaha perorangan yang memenuhi kriteria usaha mikro". Pasal 6 menjelaskan bahwa kriteria usaha mikro yaitu "usaha yang memiliki kekayaan bersih paling banyak Rp 50.000.000 (lima puluh juta rupiah) tidak termasuk tanah dan bangunan. Selain itu, suatu usaha dikatakan sebagai usaha mikro apabila memiliki hasil penjualan tahunan paling banyak Rp 300.000.000 (tiga ratus juta rupiah).” Sementara itu, pengertian usaha kecil adalah "usaha ekonomi produktif yang berdiri sendiri dan dilakukan oleh orang perorangan atau badan usaha yang bukan merupakan anak perusahaan atau bukan cabang perusahaan yang dimiliki, dikuasai, atau menjadi bagian baik langsung maupun tidak langsung dari usaha menengah atau usaha besar yang memenuhi kriteria usaha kecil". Kriteria yang digunakan untuk menjelaskan usaha kecil adalah "kekayaan bersih lebih dari Rp 50.000.000 (lima puluh juta rupiah) sampai dengan paling banyak $\mathrm{Rp} 500.000 .000$ (lima ratus juta rupiah) tidak termasuk tanah dan bangunan tempat usaha. Selain itu, usaha tersebut juga memiliki hasil penjualan tahunan sebesar lebih dari Rp 300.000.000 (tiga ratus juta rupiah) sampai dengan paling banyak $\mathrm{Rp} 2.500 .000 .000$ (dua miliar lima ratus juta rupiah).

Pengertian usaha menengah yang disebutkan dalam UU Nomor 28 Tahun 2008 adalah "usaha ekonomi produktif yang berdiri sendiri dan dilakukan oleh orang perorangan atau badan usaha yang bukan merupakan anak perusahaan atau cabang perusahaan yang dimiliki, dikuasai, atau menjadi bagian baik langsung maupun tidak langsung dari usaha kecil atau usaha besar". Kriteria usaha yang digunakan adalah "jumlah kekayaan bersih lebih dari Rp 500.000.000 (lima ratus juta rupiah) sampai dengan paling banyak Rp10.000.000.000 (sepuluh miliar rupiah) tidak 
termasuk tanah dan bangunan tempat usaha. Usaha tersebut diatas juga memiliki hasil penjualan tahunan sebesar lebih dari Rp 2.500.000.000 (dua miliar lima ratus juta rupiah) sampai dengan paling banyak Rp 50.000.000.000 (lima puluh miliar rupiah)."

Tambunan (2012) menyebutkan bahwa berdasarkan Teori Klasik (lihat Morse, 1965) ada beberapa tiga kriteria UKM, yaitu: (a) UKM berdasarkan lokasi usaha; (b) UKM berdasarkan proses pengolahan produk; dan (c) UKM berdasarkan pasar atau tipe produk yang dihasilkan. Lebih lanjut, Tambunan (2012) menjelaskan bahwa berdasarkan Teori Modern (lihat Piore \& Sable, 1983) bahwa ada kecenderungan UKM menjadi perusahaan yang mempunyai pekerja dengan keterampilan tinggi, menggunakan mesin yang fleksibel yang mengandung teknologi dan membuat sejumlah produk khusus, dalam volume kecil, dan untuk pasar global. Selain itu, UKM juga cenderung mempunyai peran signifikan dalam penciptaan lapangan pekerjaan/pengurangan angka pengangguran (Kuncoro, 2007).

Menurut Lau dan Yotopoulos (1971) dalam Kurniawan (2008), konsep efisiensi dibedakan menjadi tiga, yaitu: (a) efisiensi teknis (technical efficiency) yang mengukur tingkat produksi yang dicapai dalam penggunaan input tertentu; (b) Efisiensi alokatif; dan (c) efisiensi biaya yang keduanya mengukur tingkat keberhasilan pelaku usaha dalam mencapai keuntungan maksimum.

Selain itu, efisiensi juga dapat dilihat dari sisi efisiensi produktif. Efisiensi ini tidak hanya menjadi perhatian bagi akademisi tetapi juga pengambil kebijakan. Efisiensi produktif menekankan ukuran efisiensi berdasarkan kurva isoquant sebagai tingkat produksi maksimum dan menekan biaya pada tingkat yang minimum dalam pasar persaingan sempurna (lihat Farrell, 1957). Pada kasus UKM, ada beberapa tahapan pertumbuhan usaha yang relevan dengan capaian tingkat efisiensinya. Anderson (1982) mengidentifikasi 3 tahapan UKM, yaitu: pembangunan usaha skala mikro, pergeseran usaha skala mikro oleh usaha skala UKM, dan dominasi usaha skala besar untuk menggantikan usaha skala UKM.

Pengukuran tingkat efisiensi yang telah banyak dilakukan dalam studi empiris adalah menggunakan pendekatan data envelopment analysis (DEA). Beberapa kriteria yang terdapat dalam DEA telah diidentifikasi oleh Bowlin (1998), yaitu: (a) positivity yang menjelaskan bahwa semua variabel input dan output bernilai positif; (b) isotonicity bahwa ada kecenderungan kenaikan input akan direspon oleh kenaikan output; (c) jumlah decision making unit (DMU) minimal 3 kali jumlah kombinasi input dan output untuk menghasilkan degree of freedom yang tepat; (d) windows analysis yang menggambarkan stabilitas nilai DMU; (e) penentuan bobot dalam analisis DEA; dan (f) homogeneity menjelaskan bahwa variabel input dan output mempunyai karakteristik yang sama dan bernilai positif. Lebih lanjut, Tasman (2008) menjelaskan bahwa DEA mempunyai dua asumsi dasar, yaitu: constant return to scale (CRS) dan variable return to scale (VRS). CRS disebut juga sebagai model CCR (Charnes, Cooper and Rhodes) yang menjelaskan penambahan input akan berimplikasi pada penambahan output yang proporsional. Sementara itu, VRS disebut sebagai model BCR (Banker, Charnes and Rhodes) yang menekankan bahwa penambahan input akan berimplikasi pada penambahan output yang lebih besar.

Beberapa studi empiris telah menganalisis tingkat efisiensi usaha dengan beberapa perbedaan fokus kajian seperti efisiensi UKM di wilayah perkotaan (investasi tinggi) dan luar perkotaan (investasi rendah) di Korea (Yang, 2006), kontribusi indikator bisnis terhadap capaian efisiensi UKM di Thailand (Charoenrat \& Harvie, 2014), dan kontribusi inovasi dalam meningkatkan efisiensi bisnis (Papetti, Marilungo, Gregori, \& Germani, 2016).

Yang (2006) mengestimasi efisiensi teknis, indeks produktivitas dan pemanfaatan sumberdaya input UKM di Korea selama periode 2000-2002. Hasil penelitian menunjukkan bahwa efisiensi perusahaan skala besar relatif tinggi, distribusi ekuitas bisnis relatif tersebar ke seluruh wilayah, tenaga kerja terampil mendorong efektivitas produksi. Namun demikian, program pendanaan pemerintah terhadap UKM tidak dapat mendorong UKM berkembang secara signifikan. Lebih lanjut, studi yang mengaitkan antara tingkat efisiensi UKM dan indikator bisnis di Thailand pada tahun 1997 dan 2007 menunjukkan bahwa skala perusahaan, usia perusahaan, 
tenaga kerja terampil, lokasi usaha, kepemikan perusahaan, bantuan pemerintah, investasi asing dan transaksi ekspor berkontribusi signifikan terhadap efisiensi teknis. Hasil ini merupakan kesimpulan dari studi Charoenrat \& Harvie (2014). Selain itu, Papetti, Marilungo, Gregori, \& Germani (2016) menyimpulkan bahwa ada tiga indikator penting dalam mendorong efisiensi bisnis, yaitu: keberlanjutan, hemat/perampingan bisnis, dan inovasi. Inovasi yang tidak memadai akan berimplikasi terhadap risiko inefisiensi.

\section{METODE PENELITIAN}

Penelitian ini menggunakan data sekunder UKM di Karesidenan Surakarta. Data tersebut terdistribusi ke dalam 9 sektor pada tahun 2015-2016. Kelengkapan dan ketersediaan data sebagai variabel input dan output di masing-masing daerah dapat dilihat pada Tabel 2. Sembilan sektor ekonomi yang diteliti terdiri atas: (a) pertanian, peternakan, kehutanan dan perikanan; (b) pertambangan dan penggalian; (c) industri pengolahan; (d) listrik, gas, dan air bersih; (e) konstruksi; (f) perdagangan, hotel, dan restoran; (g) pengangkutan dan komunikas; (h) keuangan, real estate, dan jasa keuangan; dan (i) jasa-jasa.

Metode Data Envelopment Analysis (DEA) merupakan metode non-parametrik yang berbasis programasi linier. DEA pertama kali digunakan oleh Farrel (1957) yang menjelaskan efisiensi produksi (yang selanjutnya disebut sebagai efisiensi teknis) dan efisiensi ekonomi. Efisiensi tersebut dapat diukur menggunakan orientasi input. Perusahaan dikatakan efisien apabila memiliki kemampuan dalam meminimalkan input yang digunakan untuk menghasilkan output tertentu. Sementara itu, Coelli, et al (2005) menjelaskan bahwa nilai DEA adalah antara 0 (tidak efisien) - 1 (efisien) yang diperlukan untuk menentukan orientasi input terhadap output unit usaha yang diteliti.

Tabel 2. Data Penelitian di Karesidenan Surakarta

\begin{tabular}{llccccc}
\hline No & \multicolumn{1}{c}{ Daerah } & $\begin{array}{c}\text { Tenaga } \\
\text { Kerja }\end{array}$ & Modal & Omset & Asset & Keuntungan \\
\hline 1. & Surakarta & $\sqrt{ }$ & - & $\sqrt{ }$ & - & - \\
2. & Boyolali & - & - & - & - & - \\
3. & Sukoharjo & $\sqrt{ }$ & - & $\sqrt{ }$ & $\sqrt{ }$ & $\sqrt{ }$ \\
4. & Karanganyar & $\sqrt{ }$ & - & $\sqrt{ }$ & $\sqrt{ }$ & $\sqrt{ }$ \\
5. & Wonogiri & $\sqrt{ }$ & - & $\sqrt{ }$ & - & - \\
6. & Sragen & $\sqrt{ }$ & - & $\sqrt{ }$ & $\sqrt{ }$ & - \\
7. & Klaten & - & - & - & - & - \\
\hline
\end{tabular}

Coelli, et al. (2005) menjelaskan bahwa pengolahan data dengan metode DEA menghasilkan nilai efisiensi antara 0 hingga 1. Apabila skor efisiensi 0 maka dapat dikatakan semakin tidak efisien suatu hal yang diteliti. Namun, apabila skor efisiensi mendekati 1 maka menunjukkan kinerja yang efisien. Lebih lanjut, informasi input dan output sangat dibutuhkan dalam penghitungan skor efisiensi dan diperlukan dalam menentukan orientasi mana yang akan digunakan dalam penelitian ini. Selain itu, DEA merupakan pendekatan orientasi data yang digunakan dalam mengevaluasi kinerja dari Decision Making Units (DMU) yang mengubah sekumpulan input menjadi beberapa output tertentu atau dengan kata lain membandingkan rasio antara output dengan input dari semua unit yang dibandingkan. DMU adalah unit produksi yang mengubah berbagai faktor input menjadi output. Berbagai jenis entitas yang terlibat dalam banyak kegiatan telah menggunakan DEA dalam mengevaluasi kinerjanya (Cooper, Seiford \& Zhu, 2004). 


\section{HASIL DAN PEMBAHASAN}

\section{Hasil Perhitungan Efisiensi Teknis}

Hasil perhitungan efisiensi teknis UKM di Karesidenan Surakarta tahun 2015 dapat dilihat pada Tabel 3 sedangkan hasil efisiensi teknis UKM tahun 2016 dapat dicermati pada Tabel 4. Secara umum, tingkat efisiensi teknis UKM tahun 2015 dan 2016 cenderung tidak efisien. Misalnya, UKM yang tidak efisien berada di sektor pertanian, peternakan, kehutanan dan perikanan; pertambangan dan penggalian; perdagangan, hotel dan restoran; pengangkutan dan komunikasi; keuangan, real estate, dan jasa keuangan; dan jasa-jasa. Sementara itu, UKM yang efisien berada di sektor industri pengolahan; dan listrik, gas dan air bersih (kecuali di Kabupaten Sukoharjo).

Nilai efisiensi teknis UKM tahun 2015 yang relatif rendah juga terjadi pada tahun 2016. Hal ini menginformasikan bahwa pelaku usaha UKM relatif sulit untuk mengelola dan menjamin ketersediaan input yang berkualitas dan terjangkau dalam rangka menghasilkan output yang kompetitif. Selain itu, proses produksi untuk mengubah input menjadi output juga tidak dapat dilakukan secara tepat dan maksimal.

Yang (2006) menyebutkan bahwa UKM di Korea mempunyai tingkat produktivitas yang cenderung meningkat. UKM yang didukung oleh modal usaha dan tenaga kerja memadai dan terampil cenderung lebih efisien. Sementara itu, Le \& Harvie (2010) mendeskripsikan bahwa efisiensi teknis UKM di Vietnam antara 84,2\% sampai 92,5\%. Faktor-faktor yang signifikan mempengaruhi tingkat efisiensi teknis tersebut adalah umur perusahaan, skala usaha, lokasi, kepemilikan, kerjasama dengan mitra luar negeri, inovasi produk, kompetisi, dan bantuan pemerintah.

Tabel 3. Efisiensi Teknis UKM Menurut Sektor Ekonomi di Karesidenan Surakarta Tahun 2015

\begin{tabular}{|c|c|c|c|c|c|c|}
\hline \multirow{2}{*}{ No } & \multirow{2}{*}{ Sektor Ekonomi } & \multicolumn{5}{|c|}{ Kota/Kabupaten } \\
\hline & & Sukoharjo & Surakarta & Karanganyar & Wonogiri & Sragen \\
\hline 1 & $\begin{array}{l}\text { Pertanian, Peternakan, } \\
\text { Kehutanan dan } \\
\text { Perikanan }\end{array}$ & 1,000 & 0,256 & 1,000 & 0,995 & 1,000 \\
\hline 2 & $\begin{array}{l}\text { Pertambangan dan } \\
\text { Penggalian }\end{array}$ & 1,000 & 0,739 & 0,472 & 1,000 & 0,254 \\
\hline 3 & Industri Pengolahan & 1,000 & 1,000 & 1,000 & 1,000 & 1,000 \\
\hline 4 & $\begin{array}{l}\text { Listrik, Gas, dan Air } \\
\text { Bersih }\end{array}$ & 0,679 & 1,000 & 1,000 & 1,000 & 1,000 \\
\hline 5 & Konstruksi & 0,962 & 0,400 & 1,000 & 0,324 & 1,000 \\
\hline 6 & $\begin{array}{l}\text { Perdagangan, Hotel, dan } \\
\text { Restoran }\end{array}$ & 0,845 & 0,776 & 0,297 & 1,000 & 0,558 \\
\hline 7 & $\begin{array}{l}\text { Pengangkutan dan } \\
\text { Komunikasi }\end{array}$ & 1,000 & 0,185 & 0,259 & 0,215 & 0,084 \\
\hline 8 & $\begin{array}{l}\text { Keuangan, Real Estate, } \\
\text { dan Jasa Keuangan }\end{array}$ & 0,370 & 0,875 & 0,105 & 0,355 & 0,055 \\
\hline 9 & Jasa-Jasa & 0,790 & 1,000 & 0,697 & 0,823 & 0,374 \\
\hline & Rata-Rata & 0,850 & 0,692 & 0,648 & 0,746 & 0,592 \\
\hline
\end{tabular}

Terhadap empat sektor ekonomi di Kabupaten Sukoharjo pada tahun 2015 yang mempunyai nilai efisiensi teknis sama dengan 1 sedangkan pada tahun berikutnya sektor tersebut menjadi enam. Hal ini mengindikasikan bahwa ada kemajuan yang signifikan di Kabupaten Sukoharjo terkait dengan capaian efisiensi teknis usaha UKM. Selain itu, pemerintah daerah ini mempunyai keberpihakan yang signifikan terhadap perkembangan UKM. Dua daerah lain yang 
mempunyai peningkatan jumlah sektor ekonomi dengan capaian tingkat efisiensi sama dengan 1 adalah Kabupaten Karanganyar dan Wonogiri. Kedua daerah tersebut mempunyai wilayah yang relevan untuk pengembangan UKM dan terinteraksi langsung dengan perbatasan Provinsi Jawa Timur. Sementara itu, Kota Surakarta dan Kabupaten Sragen belum mampu mendorong peningkatan jumlah sektor ekonomi yang efisien pada skala UKM.

Kemampuan UKM dalam mempertahankan kegiatan bisnis dan tingkat efisiensinya dapat difasilitasi oleh pemerintah daerah maupun pusat. Kontribusi UKM dibeberapa negara juga signifikan terhadap perekonomian domestic. Charoenrat \& Harvie (2014) menjelaskan bahwa pada periode krisis ekonomi tahun 1997-1998 UKM di Thailand mempunyai tingkat efisiensi teknis yang cenderung menurun. Untuk itu, kebijakan UKM dapat diarahkan pada peningkatan kapasitas dan kapabilitas UKM, peningkatan kualitas tenaga kerja, peningkatan kualitas wirausaha, peningkatan modal dan pemanfaatan teknologi. Lebih lanjut, Le, $\mathrm{Vu} \&$ Nghiem (2018) menyebutkan bahwa UKM di Vietnam yang berada di perkotaan cenderung lebih efisien karena kemudahan akses terhadap input produksi.

Tabel 4. Efisiensi Teknis UKM Menurut Sektor Ekonomi di Karesidenan Surakarta Tahun 2016

\begin{tabular}{|c|c|c|c|c|c|c|}
\hline \multirow{2}{*}{ No } & \multirow{2}{*}{ Sektor Ekonomi } & \multicolumn{5}{|c|}{ Kota/Kabupaten } \\
\hline & & Sukoharjo & Surakarta & Karanganyar & Wonogiri & Sragen \\
\hline 1 & $\begin{array}{l}\text { Pertanian, Peternakan, } \\
\text { Kehutanan dan } \\
\text { Perikanan }\end{array}$ & 1,000 & 0,271 & 1,000 & 1,000 & 1,000 \\
\hline 2 & $\begin{array}{l}\text { Pertambangan dan } \\
\text { Penggalian }\end{array}$ & 1,000 & 0,725 & 0,444 & 1,000 & 0,239 \\
\hline 3 & Industri Pengolahan & 1,000 & 1,000 & 1,000 & 1,000 & 1,000 \\
\hline 4 & $\begin{array}{l}\text { Listrik, Gas, dan Air } \\
\text { Bersih }\end{array}$ & 0,717 & 1,000 & 1,000 & 1,000 & 1,000 \\
\hline 5 & Konstruksi & 1,000 & 0,408 & 1,000 & 0,345 & 1,000 \\
\hline 6 & $\begin{array}{l}\text { Perdagangan, Hotel, } \\
\text { dan Restoran }\end{array}$ & 1,000 & 0,789 & 0,287 & 1,000 & 0,329 \\
\hline 7 & $\begin{array}{l}\text { Pengangkutan dan } \\
\text { Komunikasi }\end{array}$ & 1,000 & 0,193 & 1,000 & 0,222 & 0,081 \\
\hline 8 & $\begin{array}{l}\text { Keuangan, Real Estate, } \\
\text { dan Jasa Keuangan }\end{array}$ & 0,295 & 0,834 & 0,105 & 0,379 & 0,061 \\
\hline 9 & Jasa-Jasa & 0,765 & 1,000 & 0,784 & 0,852 & 0,352 \\
\hline & Rata-Rata & 0,864 & 0,691 & 0,735 & 0,755 & 0,562 \\
\hline
\end{tabular}

\section{Hasil Perhitungan Efisiensi Biaya}

Tabel 5 dan 6 menginformasikan hasil perhitungan efisiensi biaya UKM di 9 sektor ekonomi tahun 2015 dan 2016. Hasil perhitungan efisiensi biaya UKM menunjukkan bahwa ada dua sektor ekonomi yang cenderung mampu menghasilkan nilai efisiensi biaya, yaitu: sektor industri pengolahan; listrik, gas dan air bersih. Hasil ini dapat menjadi pertimbangan para pelaku usaha UKM bahwa pengelolaan input yang cukup tepat untuk menghasikan output maksimal di dua sektor tersebut dapat diterapkan di sektor lainnya.

Terhadap tiga kabupaten yang mempunyai distribusi UKM dengan tingkat efisiensi biaya sama dengan 1 dengan jumlah minimal sektor ekonomi empat pada tahun 2015-2016, yaitu: Kabupaten Sukoharjo, Karanganyar, Wonogiri dan Sragen. Sektor industri pengolahan merupakan industri yang konsisten efisien di daerah-daerah tersebut. Hal ini menjelaskan bahwa daerah-daerah tersebut menyediakan input yang mencukupi sebagai faktor produksi usaha skala 
UKM. Selain itu, kecenderungan pasar hasil produk industri pengolahan terutama makanan, minuman, dan kerajinan adalah relevan berkembang di daerah tersebut.

Kemampuan pelaku UKM untuk menekan biaya produksi menjadi salah satu keunggulan manajemen produksi mereka. Dengan demikian, pemerintah daerah dapat memperkuat fasilitasi berbagai program/bantuan/pendampingan yang relevan untuk mempertahankan komponen biaya produksi yang murah. Namun demikian, pelaku usaha UKM dan pemerintah daerah tetap dapat berupaya meningkatkan kualitas produk dan jangkauan pasar baik bahan baku maupun produk UKM tersebut. Hal ini dilakukan untuk mengantisipasi fenomena demand pull maupun cost push inflation yang terjadi secara musiman. Ketidakmampuan pelaku UKM mempertahankan ketersediaan dan keterjangkauan harga bahan baku dan produk pada periode musiman akan berimplikasi terhadap tingkat efisiensi biaya usaha.

Tabel 5. Efisiensi Biaya UKM Menurut Sektor Ekonomi di Karesidenan Surakarta Tahun 2015

\begin{tabular}{|c|c|c|c|c|c|c|}
\hline \multirow{2}{*}{ No } & \multirow{2}{*}{ Sektor Ekonomi } & \multicolumn{5}{|c|}{ Kota/Kabupaten } \\
\hline & & Sukoharjo & Surakarta & Karanganyar & Wonogiri & Sragen \\
\hline 1 & $\begin{array}{l}\text { Pertanian, Peternakan, } \\
\text { Kehutanan dan } \\
\text { Perikanan }\end{array}$ & 1,000 & 0,256 & 1,000 & 0,995 & 1,000 \\
\hline 2 & $\begin{array}{l}\text { Pertambangan dan } \\
\text { Penggalian }\end{array}$ & 1,000 & 0,739 & 0,472 & 1,000 & 0,254 \\
\hline 3 & Industri Pengolahan & 1,000 & 1,000 & 1,000 & 1,000 & 1,000 \\
\hline 4 & $\begin{array}{l}\text { Listrik, Gas, dan Air } \\
\text { Bersih }\end{array}$ & 0,679 & 1,000 & 1,000 & 1,000 & 1,000 \\
\hline 5 & Konstruksi & 0,962 & 0,400 & 1,000 & 0,324 & 1,000 \\
\hline 6 & $\begin{array}{l}\text { Perdagangan, Hotel, } \\
\text { dan Restoran }\end{array}$ & 0,845 & 0,776 & 0,297 & 1,000 & 0,558 \\
\hline 7 & $\begin{array}{l}\text { Pengangkutan dan } \\
\text { Komunikasi }\end{array}$ & 1,000 & 0,185 & 0,259 & 0,215 & 0,084 \\
\hline 8 & $\begin{array}{l}\text { Keuangan, Real Estate, } \\
\text { dan Jasa Keuangan }\end{array}$ & 0,370 & 0,875 & 0,105 & 0,355 & 0,055 \\
\hline 9 & Jasa-Jasa & 0,790 & 1,000 & 0,697 & 0,823 & 0,374 \\
\hline & Rata-Rata & 0,850 & 0,692 & 0,648 & 0,746 & 0,592 \\
\hline
\end{tabular}

Tabel 6. Efisiensi Biaya UKM Menurut Sektor Ekonomi di Karesidenan Surakarta Tahun 2016

\begin{tabular}{llccccc}
\hline \multirow{2}{*}{ No } & \multicolumn{2}{c}{ Sektor Ekonomi } & \multicolumn{5}{c}{ Kota/Kabupaten } \\
\cline { 2 - 6 } & Sukoharjo & Surakarta & Karanganyar & Wonogiri & Sragen \\
\hline 1 & $\begin{array}{l}\text { Pertanian, Peternakan, } \\
\text { Kehutanan dan }\end{array}$ & 1,000 & 0,271 & 1,000 & 1,000 & 1,000 \\
& & & & & \\
2 & $\begin{array}{l}\text { Perikanan } \\
2\end{array}$ & 1,000 & 0,725 & 0,444 & 1,000 & 0,239 \\
& $\begin{array}{l}\text { Pertambangan dan } \\
\text { Penggalian }\end{array}$ & 1,000 & 1,000 & 1,000 & 1,000 & 1,000 \\
3 & Industri Pengolahan & 0,717 & 1,000 & 1,000 & 1,000 & 1,000 \\
4 & Listrik, Gas, dan Air & 1,000 & 0,408 & 1,000 & 0,345 & 1,000 \\
& Bersih & 1,000 & 0,789 & 0,287 & 1,000 & 0,329 \\
5 & Konstruksi & & & & &
\end{tabular}


Tia Putri Ariyani dan Malik Cahyadin : Pengukuran Tingkat Efisiensi Usaha Kecil Dan Menengah Di Karesidenan Surakarta Tahun 2015-2016

\begin{tabular}{|c|c|c|c|c|c|c|}
\hline 7 & $\begin{array}{l}\text { Pengangkutan dan } \\
\text { Komunikasi }\end{array}$ & 1,000 & 0,193 & 1,000 & 0,222 & 0,081 \\
\hline 8 & $\begin{array}{l}\text { Keuangan, Real Estate, } \\
\text { dan Jasa Keuangan }\end{array}$ & 0,295 & 0,834 & 0,105 & 0,379 & 0,061 \\
\hline 9 & Jasa-Jasa & 0,765 & 1,000 & 0,784 & 0,852 & 0,352 \\
\hline & Rata-Rata & 0,864 & 0,691 & 0,735 & 0,755 & 0,562 \\
\hline
\end{tabular}

Salah satu kelemahan pelaku UKM dalam mempertahankan efisiensi bisnis adalah produktivitas. Hal ini relevan dengan studi empiris yang dilakukan oleh Purwanto, Manongga \& Pakereng (2014) menunjukkan bahwa produktivitas menjadi salah satu faktor penting pencapaian efisiensi usaha Tahu (Tofu) di Kota Salatiga. Untuk itu, pelaku usaha dapat memaksimalkan output dengan keterbatasan sumberdaya (input) produksi.

\section{Hasil Perhitungan Efisiensi Alokatif}

Tabel 7 dan 8 mendeskripsikan hasil perhitungan efisiensi alokatif UKM menurut 9 sektor ekonomi di Karesidenan Surakarta tahun 2015 dan 2016. Hasil perhitungan ini menunjukkan bahwa semua UKM cenderung efisien. Hal ini memberikan informasi yang penting dalam rangka pengelolaan usaha UKM. Tingkat efisiensi ini dapat digunakan untuk mendorong peningkatan kinerja usaha dan keberlanjutannya.

Tabel 7. Efisiensi Alokatif UKM Menurut Sektor Ekonomi di Karesidenan Surakarta Tahun 2015

\begin{tabular}{|c|c|c|c|c|c|c|}
\hline \multirow{2}{*}{ No } & \multirow{2}{*}{ Sektor Ekonomi } & \multicolumn{5}{|c|}{ Kota/Kabupaten } \\
\hline & & Sukoharjo & Surakarta & Karanganyar & Wonogiri & Sragen \\
\hline 1 & $\begin{array}{l}\text { Pertanian, Peternakan, } \\
\text { Kehutanan dan } \\
\text { Perikanan }\end{array}$ & 1,000 & 1,000 & 1,000 & 1,000 & 1,000 \\
\hline 2 & $\begin{array}{l}\text { Pertambangan dan } \\
\text { Penggalian }\end{array}$ & 1,000 & 1,000 & 1,000 & 1,000 & 1,000 \\
\hline 3 & Industri Pengolahan & 1,000 & 1,000 & 1,000 & 1,000 & 1,000 \\
\hline 4 & $\begin{array}{l}\text { Listrik, Gas, dan Air } \\
\text { Bersih }\end{array}$ & 1,000 & 1,000 & 1,000 & 1,000 & 1,000 \\
\hline 5 & Konstruksi & 1,000 & 1,000 & 1,000 & 1,000 & 1,000 \\
\hline 6 & $\begin{array}{l}\text { Perdagangan, Hotel, } \\
\text { dan Restoran }\end{array}$ & 1,000 & 1,000 & 1,000 & 1,000 & 1,000 \\
\hline 7 & $\begin{array}{l}\text { Pengangkutan dan } \\
\text { Komunikasi }\end{array}$ & 1,000 & 1,000 & 1,000 & 1,000 & 1,000 \\
\hline 8 & $\begin{array}{l}\text { Keuangan, Real Estate, } \\
\text { dan Jasa Keuangan }\end{array}$ & 1,000 & 1,000 & 1,000 & 1,000 & 1,000 \\
\hline 9 & Jasa-Jasa & 1,000 & 1,000 & 1,000 & 1,000 & 1,000 \\
\hline & Rata-Rata & 1,000 & 1,000 & 1,000 & 1,000 & 1,000 \\
\hline
\end{tabular}


Tabel 8. Efisiensi Alokatif UKM Menurut Sektor Ekonomi di Karesidenan Surakarta Tahun 2016

\begin{tabular}{|c|c|c|c|c|c|c|}
\hline \multirow{2}{*}{ No } & \multirow{2}{*}{ Sektor Ekonomi } & \multicolumn{5}{|c|}{ Kota/Kabupaten } \\
\hline & & Sukoharjo & Surakarta & Karanganyar & Wonogiri & Sragen \\
\hline 1 & $\begin{array}{l}\text { Pertanian, Peternakan, } \\
\text { Kehutanan dan } \\
\text { Perikanan }\end{array}$ & 1,000 & 1,000 & 1,000 & 1,000 & 1,000 \\
\hline 2 & $\begin{array}{l}\text { Pertambangan dan } \\
\text { Penggalian }\end{array}$ & 1,000 & 1,000 & 1,000 & 1,000 & 1,000 \\
\hline 3 & Industri Pengolahan & 1,000 & 1,000 & 1,000 & 1,000 & 1,000 \\
\hline 4 & $\begin{array}{l}\text { Listrik, Gas, dan Air } \\
\text { Bersih }\end{array}$ & 1,000 & 1,000 & 1,000 & 1,000 & 1,000 \\
\hline 5 & Konstruksi & 1,000 & 1,000 & 1,000 & 1,000 & 1,000 \\
\hline 6 & $\begin{array}{l}\text { Perdagangan, Hotel, } \\
\text { dan Restoran }\end{array}$ & 1,000 & 1,000 & 1,000 & 1,000 & 1,000 \\
\hline 7 & $\begin{array}{l}\text { Pengangkutan dan } \\
\text { Komunikasi }\end{array}$ & 1,000 & 1,000 & 1,000 & 1,000 & 1,000 \\
\hline 8 & $\begin{array}{l}\text { Keuangan, Real Estate, } \\
\text { dan Jasa Keuangan }\end{array}$ & 1,000 & 1,000 & 1,000 & 1,000 & 1,000 \\
\hline 9 & Jasa-Jasa & 1,000 & 1,000 & 1,000 & 1,000 & 1,000 \\
\hline & Rata-Rata & 1,000 & 1,000 & 1,000 & 1,000 & 1,000 \\
\hline
\end{tabular}

Efisiensi alokatif yang menekankan keuntungan maksimal dengan menekan tingkat biaya produksi dapat dilakukan dengan baik oleh semua pelaku UKM di lima daerah. Hal ini mengindikasikan bahwa orientasi bisnis dalam bentuk profit oriented telah dimiliki oleh pelaku usaha. Kondisi ini menjadi nilai tambah bagi pelaku usaha UKM untuk meningkatkan efisiensi bisnisnya dalam mencapai laba usaha yang maksimal. Namun demikian, skala usaha UKM yang relatif banyak di daerah penelitian tidak hanya memfokuskan pada orientasi laba usaha yang tinggi tetapi juga keberlanjutan usaha dan jangkauan pasar yang lebih luas.

Ada kecenderungan bahwa semakin tinggi skala usaha akan menghasilkan tingkat efisiensi yang lebih baik. Penelitian yang dilakukan oleh Quayes \& Khalily (2014) menunjukkan bahwa usaha mikro di Bangladesh mempunyai tingkat efisiensi yang lebih tinggi pada skala usaha yang semakin tinggi. Artinya, usaha mikro dengan skala usaha lebih tinggi dibandingkan usaha mikro lainnya mempunyai tingkat efisiensi yang lebih tinggi juga. Lebih lanjut, Pérez-Gómez, ArbeloPérez \& Arbelo (2018) mendeskripsikan bahwa UKM di Spanyol mempunyai tingkat efisiensi laba antara 45,57\% - 55,13\% (rata-rata sebesar 49.37\%).

\section{SIMPULAN}

Penelitian ini memfokuskan pada perhitungan efisiensi teknis, biaya dan alokatif terhadap UKM di sembilan sektor ekonomi pada tahun 2015-2016. UKM tersebut tersebar di lima wilayah yang dikenal dalam kawasan Karesidenan Surakarta. Kondisi tingkat efisiensi UKM cenderung berbeda antara satu metode dengan metode efisiensi karena perbedaan instrumen perhitungan.

Hasil perhitungan efisiensi menunjukkan bahwa terdapat 3 daerah yang mempunyai efisiensi teknis dan biaya, yaitu: Kabupaten Sukoharjo, Wonogiri, dan Karanganyar. Sementara itu, nilai rata-rata efisiensi alokatif UKM di Sukoharjo, Surakarta, Karanganyar, Sragen, dan Wonogiri masing-masing adalah sebesar 1 (100\%). Artinya UKM tersebut terkategori efisien dalam mengalokasikan dan mengkombinasikan penggunaan input untuk menghasilkan output tertentu. 
Tia Putri Ariyani dan Malik Cahyadin : Pengukuran Tingkat Efisiensi Usaha Kecil Dan Menengah Di Karesidenan Surakarta Tahun 2015-2016

Penelitian ini mendorong peran pelaku UKM untuk mampu mengelola input dan menjaga ketersediaannya dalam proses produksi. Pemerintah daerah diharapkan dapat memfasilitasi pembentukan atau pengembangan klaster UKM untuk menjamin ketersediaan input yang mencukupi dan terjangkau. Selain itu, pelaku usaha UKM dan pemerintah daerah dapat bersinergi untuk menjaga pasar UKM baik di pasar domestik maupun luar negeri.

\section{DAFTAR PUSTAKA}

Anderson, D. 1982. Small-scale Industry In Developing Countries : A Discussion of the Issues. World Development. 10 (11): 913-948.

Bowlin, W. F. 1998. Measuring Performance: an Introduction to DEA. Journal of Cost Analysis. 27(3): 3-27.

Charoenrat, T. \& Harvie, C. 2014. The efficiency of SMEs in Thai manufacturing: A stochastic frontier analysis. Economic Modelling. 43: 372-393.

Coelli, T. J., et al. 2005. An Introduction to Efficiency and Productivity Analysis. New York: Springer Science \& Business Media.

Cooper, W. W., Seiford, L. M., \& Zhu, J. 2004. Handbook on Data Envelopment Analysis. New York: Springer.

Fajar, M. N. D. 2016. UKM di Indonesia Perspektif Hukum Ekonomi. Yogyakarta: Pustaka Pelajar.

Farrell, M. J. 1957. The Measurement of Productive Efficiency. Journal of the Royal Statistical Society: Series A (General). 120 (3): 253-290.

Holban, I. \& Razvan, F. 2009. Internationalization of SME's in the Context of the Economic Crisis. Economic and Applied Informatics. 45-50.

Horbach, J. 2016. The Impact of Resources Efficiency Measures on Performance in Small and Medium-sized Enterprises. Ruhr Economic Papers No. 643.

Kuncoro, M. 2007. Ekonomika Industri Indonesia: Menuju Negara Industri 2030?. Yogyakarta: Penerbit ANDI.

Kurniawan, A. Y. 2008. Analisis Efisiensi Ekonomi dan Dayasaing Usahatani Jagung Pada Lahan Kering di Kabupaten Tamah Laut Kalimantan Selatan. Tesis. Bogor: Sekolah Pascasarjana IPB.

Le, V. \& Harvie, C. 2010. Firm Performance in Vietnam: Evidence from Manufacturing Small and Medium Enterprises. Economics Working Papers wp10-04,

Le, V., Vu, X.-B. (Benjamin), \& Nghiem, S. 2018. Technical efficiency of small and medium manufacturing firms in Vietnam: A stochastic meta-frontier analysis. Economic Analysis and Policy. 59: 84-91.

Madalina, B. 2013. Importance of Small and Medium-sized Enterprises in Romanian Economy. Annals-Economy Series. 4: 205-212.

Malik, H. 2015. Bangun Industri Desa Selamatkan Bangsa : Strategi Pembangunan Industri Desa di Kabupaten Kaur, Bengkulu. Bogor : PT. Penerbit IPB Press.

Miroljub, H. \& Petar, P. 2010. Small and medium enterprises in Serbia in crisis circumstances. Proceeding on 8th International Conference on Mangement, Enterprise and Benchmarking in György Kadocsa.

Papetti, A., Marilungo, E., Gregori, F. \& Germani, M. 2016. Driving process innovation: a structured method for improving efficiency in SMEs. Procedia CIRP.

Penchev, P. 1998. The Small and Medium Size Enterprises in the Industry. Economic Studies Journal. 2: 112-133.

Pérez-Gómez, P., Arbelo-Pérez, M. \& Arbelo, A. 2018. Profit Efficiency and Its Determinants In Small and Medium-Sized Enterprises in Spain. BRQ Business Research Quarterly. 21:238250.

Porcelli, F. 2009. Measurement of Technical Efficiency: A Brief Survey on Parametric and Nonparametric Techniques. University of Warwick. 
Purwanto, P., Manongga, D. \& Pakereng, M. 2014. Efficiency of Small and Medium sized Tofu Enterprises (SME) in Salatiga using Data Envelopment Analysis (DEA). International Journal of Computer Applications. 91(12).

Quayes, S. \& Khalily, B. 2014. Efficiency of Microfinance Institution in Bangladesh. Economics Bulletin. 34 (3): 1512-1521.

Tambunan, T. T. H. 2002. Usaha Kecil dan Menengah di Indonesia : Beberapa Isu Penting. Jakarta : Salemba Empat. Jakarta : LP3ES. 2012. Usaha Mikro Kecil dan Menengah di Indonesia : Isu-Isu Penting.

Tasman, A. 2008. Ekonomi Produksi, Analisis Efisiensi dan Produktivitas. Chandra Pratama. Undang-Undang Nomor 20 Tahun 2008 tentang Usaha Mikro, Kecil, dan Menengah (UMKM). Yang, J.-C. 2006. The efficiency of SMEs in the global market: Measuring the Korean performance. Journal of Policy Modeling. 28: 861-876. 